\title{
A bola, as ruas alinhadas e uma poeira infernal: os primeiros anos do futebol em Belo Horizonte, de Raphael Rajão
}

\author{
A bola, as ruas alinhadas e uma poeira infernal: os primeiros anos do \\ futebol em Belo Horizonte, by Raphael Rajão
}

Vinicius Garzon Tonet

Universidade Federal de Minas Gerais, Belo Horizonte/MG, Brasil Doutorando em História, UFMG vgtonet@gmail.com

Raphael Rajão Ribeiro resgata um valor na escrita da História muitas vezes ignorado pelos pesquisadores. Linha após linha, percebemos que os nossos olhos estão sendo guiados pelo seu amor por Belo Horizonte. Amor que se revela delicadeza no trato das fontes e esmero com aquilo que é escrito. É como se Rajão fosse uma espécie de historiador humanista investigando o passado de sua comuna e que se orgulha por cumprir o dever de servir a sua cidade amada. E isso já seria motivo suficiente para encarar as páginas de $A$ bola, as ruas alinhadas e uma poeira infernal: os primeiros anos do futebol em Belo Horizonte (1904-1921), pois como diz a frase atribuída a León Tolstoi, "Canta a tua aldeia e serás universal". Além de ser um robusto trabalho de história urbana, como ressaltado pela professora Maria Eliza Linhares Borges na apresentação do livro, é, ainda, uma rica contribuição para a história dos primórdios do futebol no Brasil.

O livro, publicado em 2018, pela Drible de Letra, é fruto de pesquisa de mestrado desenvolvida no Programa de Pós-Graduação em História, da Universidade Federal de Minas Gerais. Os textos que apresentam a história ao leitor são de Bernardo Buarque de Hollanda, que escreve na primeira orelha, Marcelino Rodrigues da Silva, que assina o prefácio e a já citada Maria Elisa Borges, que também foi a orientadora no projeto, responsável pela apresentação e quarta capa. Por sua vez, a capa do livro estampa a fotografia de um dos atores da história que nos conta Rajão, José Gonçalves, alinhadíssimo com seu uniforme do Sport Club, primeira agremiação futebolística de Belo Horizonte. 
Seguindo a linha historiográfica de José Moraes dos Santos Neto, em Visão do jogo: primórdios do futebol no Brasil (2002), e de Leonardo Pereira, em seu clássico

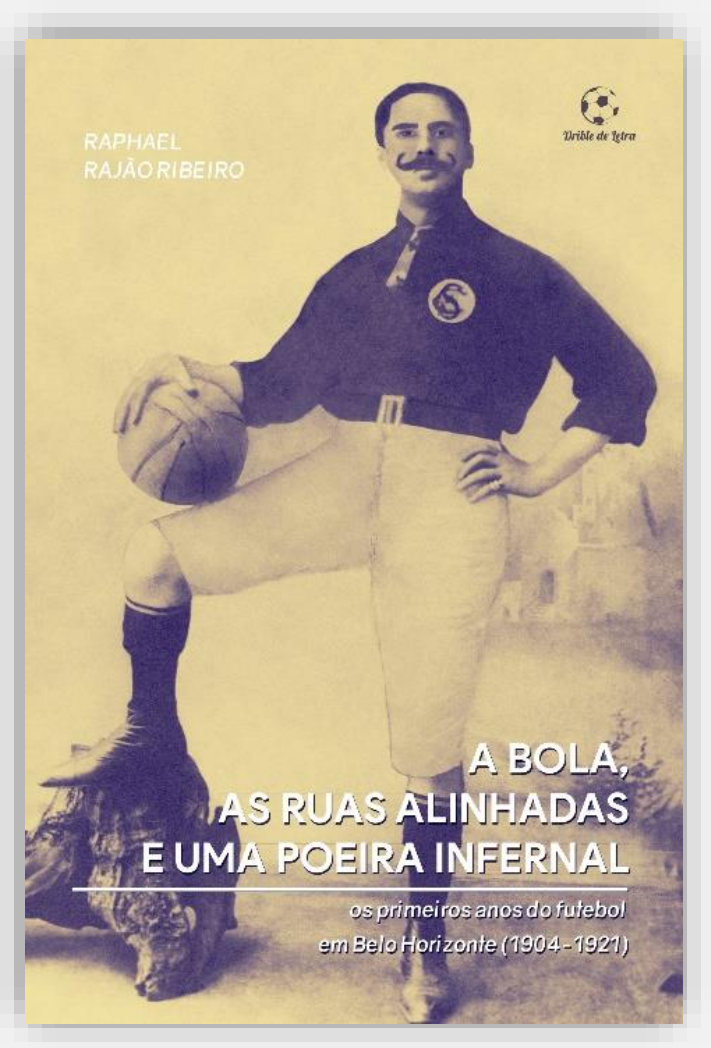

Footballmania: uma história social do futebol no Rio de Janeiro - 1902-1938 (2000), Raphael Rajão analisa os caminhos e os descaminhos tanto da prática do futebol quanto do discurso relacionado a ela em Belo Horizonte. Para isso, promove uma imersão no cotidiano dos primeiros anos da capital de Minas Gerais, trazendo à luz os atores, individuais e coletivos, que fizeram a bola rolar nos antigos estádios, nos lotes vagos, nas praças, ruas e calçadas de Beagá. A partir da observação dessa dinâmica de interação entre os sujeitos históricos, o esporte e a cidade, nasce o título do livro, que, como salientou Marcelino Rodrigues da Silva,

parece querer sintetizar as contradições que marcaram a introdução e a consolidação do futebol na recém-fundada capital mineira. As ruas alinhadas apontam para as ideologias da civilização e do progresso que inspiraram os planos da nova cidade, com seu traçado urbano regular e racionalista e sua cenografia moderna e republicana. A poeira infernal, por sua vez, remete ao estado de inacabamento em que se encontrava a cidade em seus primeiros anos [...] denunciando as falhas do projeto de modernização que ela representava. Metaforicamente, a poeira remete também ao provincianismo da população. ${ }^{1}$

Nessa empreitada, Rajão é cirúrgico ao demarcar as especificidades na formação do campo esportivo na cidade. Ao mesmo tempo, não abre mão de sublinhar uma série de semelhanças quando diferentes processos históricos são comparados.

Para construir o livro, que é dividido em três capítulos ("O futebol em Belo Horizonte e a constituição do campo esportivo", "O futebol belo-horizontino no

\footnotetext{
${ }^{1}$ SILVA. Prefácio. A bola, as ruas alinhadas e uma poeira infernal, p. 15-6.
} 
circuito da informação" e "As vivências na cidade e o futebol"), Rajão mobiliza, com elegância, fontes variadas. Jornais, revistas, fotografias, mapas, plantas arquitetônicas, decretos, leis, memórias e fontes policiais compõem o corpus documental da pesquisa. Registre-se que, para cada tipo de vestígio, o autor apresenta uma justificativa metodológica para o seu uso, assim como avalia o peso de cada uma para a composição de sua narrativa, sendo os periódicos a sua "principal referência empírica". ${ }^{2}$ Justamente por dominar a matéria-prima de seu trabalho, é que reconhece os inúmeros vazios que ainda permeiam o seu texto final. Para tentar suprir essas lacunas, Raphael Rajão procura trabalhar sob a perspectiva da análise seriada de documentação.

Todas as explicações sobre como se deu a relação com as suas fontes estão na "Introdução" do livro, juntamente com uma breve discussão bibliográfica sobre a historiografia do futebol no Brasil. Nesta revisão, Rajão posiciona-se no sentido de aprofundar a "compreensão das diferentes realidades nacionais". ${ }^{3}$ Por isso, Raphael Rajão, ao estudar o contexto de Belo Horizonte, levanta questões para tentar entender se o "desenvolvimento" do futebol "ocorreu da mesma forma em todas as cidades e regiões" e se "as narrativas consagradas", como a de Mário Filho, em O negro no futebol brasileiro (1947/1964), "são capazes de englobar um contexto que foi nacional". ${ }^{4}$

É também na etapa introdutória da obra que o autor explicita que entende o futebol, para os fins analíticos desejados, nos moldes das definições de Norbert Elias e Eric Dunning, em Quest for Excitement Sport and Leisure in the Civilizing Process (1986). Esses pensadores veem o surgimento do esporte moderno como parte integrante do processo civilizador, em que o autocontrole da violência, uniformização de regras antes dispersas e pouco reproduzíveis fora de situações particulares, assim como a racionalidade seriam as marcas das atividades esportivas. Essa opção de leitura dos fenômenos acaba enriquecendo as análises sobre Belo Horizonte, uma vez que, como já ressaltado, é uma cidade que nasce sob o signo da modernidade.

\footnotetext{
${ }^{2}$ RIBEIRO. A bola, as ruas alinhadas e uma poeira infernal, p. 31.

${ }^{3}$ RIBEIRO. A bola, as ruas alinhadas e uma poeira infernal, p. 27.

${ }^{4}$ RIBEIRO. A bola, as ruas alinhadas e uma poeira infernal, p. 22.
} 
Outra referência teórica central para Rajão é Pierre Bourdieu. Desenvolvido pelo pensador francês, o conceito de campo fornecerá as lentes principais para que Raphael Rajão investigue o passado do futebol. 0 autor assimila da seguinte maneira o léxico do sociólogo:

Em linhas gerais, [campo] pode ser definido como setor específico do universo social, historicamente produzido, espaço de relações objetivas e produção de capital social, o qual envolve lógica própria de organização interna e de distribuição de prestígio entre seus integrantes, cujas delimitações de fronteiras e de critérios de atribuição de capital simbólico são objetos de constantes disputas. ${ }^{5}$

Dessa forma, Rajão sente-se à vontade para propor a sua hipótese central, a saber, que o futebol foi o principal responsável pela formação de um campo esportivo em Belo Horizonte. Esse campo possuía suas particularidades dentro do universo social, promovendo instituições, pessoas, modos de socialização próprios a ele. Apesar de ser o foco principal do primeiro capítulo, como veremos agora, ela vai se desdobrando ao longo do livro.

Em "O futebol em Belo Horizonte e a constituição do campo esportivo", capítulo inicial, como vimos, Rajão evidencia como a Comissão Construtora da Nova Capital previu no traçado urbano da então Cidade de Minas dois espaços destinados à prática esportiva: o hipódromo e o velódromo. Contudo, às práticas relacionadas a esses espaços não tiveram a continuidade desejada pelos fundadores tanto do Velo Club quanto do Derby Mineiro. Apesar disso, diz Raphael Rajão, essas duas experiências contribuíram para efetivar espaços esportivos e mostrar àquela população provinciana que existia a possibilidade de atividades ao ar livre. Os pioneiros do futebol souberam aproveitar as virtudes das atividades precedentes para introduzir o jogo na capital. Conta Rajão que o responsável por essa introdução foi Victor Serpa, uma figura análoga a Charles Miller e Oscar Cox, acadêmico de Direito que havia estudado na Suíça e lá conhecido o futebol. Serpa criou, em 1904, o Sport Club e grupos da elite belo-horizontina entusiasmaram-se pelo jogo. 0 que se viu no biênio 1904-1905 foi uma verdadeira "mania de football", ${ }^{\circ}$ dentro do círculo da elite da cidade, com bom público indo ao Parque Municipal assistir aos

\footnotetext{
${ }^{5}$ RIBEIRO. A bola, as ruas alinhadas e uma poeira infernal, p. 30.

${ }^{6}$ RIBEIRO. A bola, as ruas alinhadas e uma poeira infernal, p. 53.
} 
jogos, com diversas equipes sendo fundadas, criação de vocabulário específico na imprensa e, desde o primeiro ano, a articulação de um campeonato. Rajão localiza aí, com o advento do futebol, o início da formação do campo esportivo que iria se consolidar anos mais tarde, precisamente na segunda metade da década de 1910.

Contudo, até o campo se consolidar, o futebol passou por momentos difíceis. O mais dramático corresponde aos anos de 1906 e 1907, logo após o falecimento de Serpa, em 1905. Apesar da euforia inicial, os clubes não conseguiram manter suas atividades, os sócios pareciam não ter tanto comprometimento com as instituições e todas as agremiações pioneiras fecharam as suas portas. Em 1908, porém, há uma revitalização nesse cenário em que "as iniciativas passadas, ainda que, a princípio, sem continuidade, constituíam lembrança que informava as tentativas posteriores de consolidação dos desportos". 7 Sobre a retomada, Rajão escreve:

Ao longo dos cinco anos posteriores ao retorno do futebol a Belo Horizonte, uma considerável intensificação das atividades das agremiações pôde ser percebida, inclusive, com o desenvolvimento de importantes elementos para a consolidação desse gênero de divertimento, como, por exemplo, espaços esportivos, público assistente e comprometido grupo de praticantes. ${ }^{8}$

Ao longo da década de 1910, portanto, percebe-se o alargamento social dos grupos de praticantes, com a fundação, por exemplo, do Yale, time de operários, do America Football Club, time de garotos impedidos de entrar em outras equipes por conta da "pouca idade"9 ou Sport Club Lusitânia, ligado à colônia portuguesa. Jornais especializados também surgem nesse cenário. Há, segundo o pesquisador, uma "diversificação do repertório da imprensa"10 agora mais atenta ao jogo. 0 futebol passa a ser praticado em instituições de ensino com professores e alunos figurando nos quadros das equipes. Rivalidades e relações de simpatia tornam-se mais presentes, espaços se multiplicam, a paixão do torcedor aparece no horizonte, assim como atos violentos, geralmente associados "às partidas das equipes pequenas e de origem social mais popular".11 Toda essa dinâmica da elaboração de paixões

\footnotetext{
${ }^{7}$ RIBEIRO. A bola, as ruas alinhadas e uma poeira infernal, p. 65.

${ }^{8}$ RIBEIRO. A bola, as ruas alinhadas e uma poeira infernal, p. 76.

${ }^{9} \mathrm{RIBEIRO}$. A bola, as ruas alinhadas e uma poeira infernal, p. 72.

${ }^{10}$ RIBEIRO. A bola, as ruas alinhadas e uma poeira infernal, p. 78.

11 RIBEIRO. A bola, as ruas alinhadas e uma poeira infernal, p. 111.
} 
clubísticas e vínculos identitários que extrapolam os laços entre futebol e sociabilidade de elite será trabalhado no terceiro capítulo.

É durante a década de 1910, mais precisamente em 1917, que também há a interferência da Confederação Brasileira de Desportes em Minas Gerais com a criação da Liga Mineira de Desportes Terrestres (LMDT) para sanar a inoperância, devido a atritos internos, da antiga Liga Mineira de Sports Athleticos (LMSA), assunto que também é trabalhado com mais fôlego no segundo capítulo do livro quando o historiador irá analisar o "desenvolvimento e limites da integração institucional regional e nacional".12 Dessa forma, no alvorecer da década de 1920 já é possível perceber a consistência do campo esportivo delineado por Rajão.

No capítulo seguinte, "O futebol belo-horizontino no circuito da informação", Raphael Rajão faz-nos ver como os agentes implicados na consolidação do campo esportivo na capital mineira "não se percebiam como isolados de um processo mais amplo"13 de "esportificação". 14 Apesar de o mundo predominante agrário no qual a cidade enraizava-se contrastar com o desejo de modernidade cultivado pelas suas elites, as "recém-criadas tecnologias", como o telégrafo, "possibilitavam que as informações circulassem de modo cada vez mais rápido e em maior quantidade". ${ }^{15}$ Era difícil ser moderno, mas neste contexto em que vontades e o estado das coisas friccionavam-se, a imprensa tornava-se um vetor do cosmopolitismo e o futebol considerado um aliado importante para a superação dos atrasos da capital. Notícias sobre o futebol em outras partes do globo, bem como sobre demais regiões do estado e do Brasil passam a fazer parte da rotina da imprensa local e a criar, como consequência, um processo de integração "entre os principais centros urbanos nacionais".16 Nesse sentido, Rajão corrobora as análises de Gilmar Mascarenhas, entendendo que a difusão informacional do futebol no Brasil deu-se em um "modelo de arquipélago"17 em que "o processo de expansão do futebol ocorreu, no caso brasileiro, de forma isolada entre os principais centros urbanos nacionais". ${ }^{18}$ Eram

\footnotetext{
12 RIBEIRO. A bola, as ruas alinhadas e uma poeira infernal, p. 150.

${ }^{13}$ RIBEIRO. A bola, as ruas alinhadas e uma poeira infernal, p. 123.

${ }^{14}$ RIBEIRO. A bola, as ruas alinhadas e uma poeira infernal, p. 118.

${ }^{15}$ RIBEIRO. A bola, as ruas alinhadas e uma poeira infernal, p. 128.

${ }^{16}$ RIBEIRO. A bola, as ruas alinhadas e uma poeira infernal, p. 122.

17 RIBEIRO. A bola, as ruas alinhadas e uma poeira infernal, p. 122.

${ }^{18}$ RIBEIRO. A bola, as ruas alinhadas e uma poeira infernal, p. 122.
} 
várias ilhas em interação, mas com processos próprios de desenvolvimento. No caso de Belo Horizonte, além da informação, circulavam equipes de outras cidades e estados, pessoas, como Olavo Bilac, "reconhecido difusor do pensamento nacionalista aplicado às práticas atléticas",19 ideias, como "a teoria eugênica" e sua "valorização do esporte como mecanismo de desenvolvimento da raça"20 e mercadorias esportivas, tudo isso favorecendo a delimitação e o avivamento do campo esportivo na cidade.

Deste modo, o futebol foi, paulatinamente, legitimando-se como prática social ligada aos divertimentos percebidos como modernos, assim como o cinema. Raphael Rajão articula muito bem como os universos imbricavam-se. A partir dessa visada, o historiador consegue ver que se o Torneio Sul-Americano de 1919 não chamou muito a atenção dos mineiros quando noticiado pelas páginas dos jornais, como na Capital do República, por exemplo, a sua exibição nas telas atraiu bom público em Belo Horizonte. Além disso, Rajão traça diferenças importantes no que diz respeito aos significados atribuídos àquela competição:

Ao que parece, não havia entusiastas do que era entendido naquele momento, como o selecionado brasileiro. Mesmo que evocada nos anúncios dos cinemas, a construção da identidade nacional vinculada ao esporte dava mostras de ainda estar longe de atingir a capital mineira, que pouco se integrava ao centro decisório do país, apesar de atenta ao que acontecia nele. ${ }^{21}$

Ao colocar a discussão sobre os "projetos de construção da identidade nacional"22 Rajão conclui que "os grandes centros nacionais não eram vistos como parte do mesmo movimento atlético. A percepção de uma unidade ainda se restringia a Belo Horizonte - para fora dali, o que se via eram outras realidades". ${ }^{23}$ Contudo, não fica muito claro qual unidade seria essa, dando a entender que se trataria da unidade do sentimento nacional, o que por sua vez entraria em contradição com palavras que vem na sequência:

\footnotetext{
${ }^{19}$ RIBEIRO. A bola, as ruas alinhadas e uma poeira infernal, p. 154.

${ }^{20}$ RIBEIRO. A bola, as ruas alinhadas e uma poeira infernal, p. 155.

${ }^{21}$ RIBEIRO. A bola, as ruas alinhadas e uma poeira infernal, p. 161.

22 RIBEIRO. A bola, as ruas alinhadas e uma poeira infernal, p. 164.

${ }^{23}$ RIBEIRO. A bola, as ruas alinhadas e uma poeira infernal, p. 164.
} 
perceber tais conexões não significa reduzir as escolhas tomadas pelos futebolistas belo-horizontinos a condicionantes externos; pelo contrário, representa ter em conta que as singularidades apresentadas pelo caso da capital mineira foram construídas com a consciência do que se passava em outras partes do Brasil e do mundo. ${ }^{24}$

Aquilo que Rajão aponta como "outras realidades", dado o ritmo do texto e a própria ideia construída de ilhas em interação - "tais conexões" -, não parece ser tão "outra" assim, tendo em vista a própria dinâmica relacional entre os núcleos de desenvolvimento do esporte. Além disso, poderíamos levantar o questionamento: mesmo com a ausência de entusiasmo, em Belo Horizonte, com os valores nacionais atribuídos à seleção brasileira, não compartilhariam os agentes da construção do campo esportivo na cidade, a partir da lógica do cosmopolitismo, tão bem elucidada pelo pesquisador, uma inclinação por participar de uma comunidade nacional imaginada pelas elites brasileiras? Ou seja, não estariam os belo-horizontinos partilhando uma ideia de nação calcada em elementos de modernização e civilidade cultivada pelas elites?

O terceiro e último capítulo, cujo título é "As vivências na cidade e o futebol", elucida como o futebol fomentou transformações no que tange à ocupação dos espaços públicos e à criação de novas formas de sociabilidade em Belo Horizonte. Como já foi dito, o plano da nova capital comportava o desejo de infundir na população um apreço pelos divertimentos ao ar livre com seus parques e praças, além dos já citados hipódromo e velódromo. Contudo, Rajão evidencia que "a maioria dos habitantes da capital mineira deva demonstrações de não compartilhar das mesmas intencionalidades daqueles que definiram o traçado inicial". ${ }^{25}$ Nos primeiros anos da vida de Belo Horizonte, apenas "alguns concertos das bandas locais" e "festividades carnavalescas"26 retiravam a população, tão afeita aos espaços privados, de seus lares, uma vez que o circuito do lazer (peças teatrais, saraus, apresentações de circo) ${ }^{27}$ acontecia "nas próprias casas dos habitantes". 28

\footnotetext{
${ }^{24}$ RIBEIRO. A bola, as ruas alinhadas e uma poeira infernal, p. 164-5.

${ }^{25}$ RIBEIRO. A bola, as ruas alinhadas e uma poeira infernal, p. 170.

${ }^{26}$ RIBEIRO. A bola, as ruas alinhadas e uma poeira infernal, p. 171.

${ }^{27}$ RIBEIRO. A bola, as ruas alinhadas e uma poeira infernal, p. 171.

${ }^{28}$ RIBEIRO. A bola, as ruas alinhadas e uma poeira infernal, p. 171.
} 
Frente a esta "recusa do convívio público",29 Raphael Rajão observa uma demanda nos discursos da imprensa que cobrava uma maior vitalidade de atividades ao ar livre. Neste ponto, as agremiações e clubes passam a ter maior visibilidade nas páginas dos jornais por serem vistos como propagadores de novas formas de sociabilidade na vida cotidiana. Destacava-se "a importância da atividade atlética",30 sua contribuição ao "desenvolvimento do corpo e do intelecto"31 e ao "autocontrole", assim como valorizava-se o esporte como "alternativa prazerosa para a realização dos exercícios"32 e como instrumento para incrementar atividades comerciais. Assim, a missão que se desvelava para essas personagens era a construção de uma nova rotina em que "uma nova forma de se vivenciar o corpo"33 e o espaço público deveria ser criada. Nesse sentido, os futebolistas, buscando espaços de jogo, faziam de "lotes vagos",34 ruas, praças e parques campos de futebol. Muitas vezes com o respaldo do poder público que "percebia tal modalidade atlética como prática útil à cidade" e que "compreendia como legítima a apropriação [...] do espaço que, a princípio, não era destinado ao esporte"35 o que fez, devido ao prestígio crescente dos clubes, com que houvesse, inclusive, a "concessão de terrenos"36 para a construção de estádios na década de 1920. Esse processo visualizado ao longo dos anos 1910, comporta, aos poucos, o "aumento da prática, inclusive em sua forma não organizada" e "com isso, cada vez mais as ruas da cidade eram tomadas pelo jogo de boa", assim como a "emergência da paixão pelo jogo se potencializou". ${ }^{37}$ Uma trajetória na qual observa-se, portanto, a construção de novas práticas e novas sociabilidades.

Contudo, como assinala Rajão, essa história não se realizou de forma linear e pacífica, já que até 1908 o entusiasmo dos "sportsmen" não se verificou no restante da população. Além disso, não era raro encontrar visões contrárias às práticas esportivas, mais especificamente ao futebol. Os críticos apontavam para o

\footnotetext{
${ }^{29}$ RIBEIRO. A bola, as ruas alinhadas e uma poeira infernal, p. 168.

${ }^{30}$ RIBEIRO. A bola, as ruas alinhadas e uma poeira infernal, p. 179.

${ }^{31}$ RIBEIRO. A bola, as ruas alinhadas e uma poeira infernal, p. 179.

32 RIBEIRO. A bola, as ruas alinhadas e uma poeira infernal, p. 179.

${ }^{33}$ RIBEIRO. A bola, as ruas alinhadas e uma poeira infernal, p. 186.

${ }^{34}$ RIBEIRO. A bola, as ruas alinhadas e uma poeira infernal, p. 205.

${ }^{35}$ RIBEIRO. A bola, as ruas alinhadas e uma poeira infernal, p. 210.

${ }^{36}$ RIBEIRO. A bola, as ruas alinhadas e uma poeira infernal, p. 219.

37 RIBEIRO. A bola, as ruas alinhadas e uma poeira infernal, p. 216.
} 
"modismo" do "costume estrangeiro"38 e o seu prejuízo à saúde, devido às lesões, bem como ao atrofiamento das capacidades intelectuais dos praticantes e o estímulo à agressividade entre praticantes. Críticas essas muito similares as vistas em outras localidades da República, como as presentes no grupo que fundou a "Liga contra o football" no Rio de Janeiro. Outro ponto que também chama a atenção do leitor é a idealização do esporte não como mero divertimento, mas a serviço do trabalho com a sugestão de um "Sport Agrícola”, no ano de 1907, que deslocaria a prática esportiva "para um novo lugar, mais próximo do setor produtivo"39 em que "disputas em torno da habilidade de se usar o arado, dentre outras, poderiam tornar o trabalho uma tarefa divertida, atraindo o interesse de famílias inteiras, que ao fim das partidas teriam realizado uma etapa do processo do plantio".40 Também é digno da atenção do pesquisador o fato desses discursos construírem a visão de que o futebol era "prática destinada aos grupos mais selecionados da sociedade local" e que "o novo esporte não serviria [...] para o lazer das classes populares", ${ }^{41}$ lógica que vai sendo subvertida com a ampliação das bases sociais dos praticantes e os novos sentidos atribuídos ao jogo.

Dessa forma, o livro cumpre a sua trajetória trazendo à luz o futebol como elemento importante para a delimitação do campo esportivo da cidade e o próprio desenvolvimento da história de Belo Horizonte. O futebol legitimado como prática pelo poder público e pelos habitantes interferiu no próprio traçado urbano da recém-fundada capital, nas formas de sociabilidade e nos gostos da população. Por vias tortas, aquilo que havia sido concebido pelos idealizadores do plano urbanístico acaba se consolidando e Rajão é hábil em evidenciar a importância da ação na história para que ideias sejam efetivadas. ${ }^{42}$

Ao mirar no que houve de específico, e são tantas as particularidades desta história como observado ao longo da resenha, Raphael Rajão encontra também um

\footnotetext{
${ }^{38}$ RIBEIRO. A bola, as ruas alinhadas e uma poeira infernal, p. 181.

${ }^{39} \mathrm{RIBEIRO}$. A bola, as ruas alinhadas e uma poeira infernal, p. 184.

${ }^{40}$ RIBEIRO. A bola, as ruas alinhadas e uma poeira infernal, p. 181.

${ }^{41}$ RIBEIRO. A bola, as ruas alinhadas e uma poeira infernal, p. 177.

42 "Tal noção de incorporação de hábitos em voga nos centros mundiais, tidos como mais desenvolvidos, perpassava não só o discurso dos planejadores da cidade, mas o de boa parte da sociedade local, especialmente a imprensa e as classes letradas". RIBEIRO. A bola, as ruas alinhadas e uma poeira infernal, p. 223.
} 
processo muito semelhante ao que ocorreu em outras localidades. Talvez, uma proposta de ampliação de sua pesquisa pudesse ser no sentido de investigar as disputas entre amadorismo e profissionalismo na constituição do campo esportivo na capital de Minas Gerais. Por fim, Rajão realiza o objetivo colocado no início de seu trabalho, a saber, o de contribuir para a compreensão de diferentes realidades nacionais estudando o caso de Belo Horizonte. Apesar de não retomar Mário Filho em sua conclusão, como o faz na introdução, podemos apontar para convergências entre aquilo que é narrado em $O$ negro no futebol brasileiro e o processo belohorizontino, como o "papel de destaque de um estudante vindo do exterior na construção da memória"43 do futebol, "o aspecto restritivo que as agremiações mantiveram no momento inicial", 44 "a constituição de agremiações em bairros afastados, as quais projetavam seus laços de vizinhança na formação da equipe e da torcida". 45 Evidentemente, essas correspondências estão longe de confirmar a ideia "do caso carioca como síntese nacional”, 46 como queria Mário Filho, pois, apesar delas, "a consolidação das práticas esportivas dialogou com as realidades locais, em um processo descontinuado de sua difusão pelo território brasileiro". ${ }^{47}$ Certamente, A bola, as ruas alinhadas e uma poeira infernal: os primeiros anos do futebol em Belo Horizonte (1904-1921) apresenta-se no horizonte como bibliografia fundamental para todos aqueles interessados em compreender a história das cidades e do futebol no início do século XX.

\footnotetext{
${ }^{43}$ RIBEIRO. A bola, as ruas alinhadas e uma poeira infernal, p. 223.

${ }^{44} \mathrm{RIBEIRO}$. A bola, as ruas alinhadas e uma poeira infernal, p. 223.

${ }^{45} \mathrm{RIBEIRO}$. A bola, as ruas alinhadas e uma poeira infernal, p. 223.

${ }^{46} \mathrm{RIBEIRO}$. A bola, as ruas alinhadas e uma poeira infernal, p. 24.

${ }^{47}$ RIBEIRO. A bola, as ruas alinhadas e uma poeira infernal, p. 225.
} 


\section{REFERÊNCIAS}

RIBEIRO, Raphael Rajão. A bola, as ruas alinhadas e uma poeira infernal: os primeiros anos do futebol em Belo Horizonte (1904-1921). Rio de Janeiro: Drible de Letra, 2018. 245p.

SILVA, Marcelino Rodrigues da. Prefácio. In: RIBEIRO, Raphael Rajão. A bola, as ruas alinhadas e uma poeira infernal: os primeiros anos do futebol em Belo Horizonte (1904-1921). Rio de Janeiro: Drible de Letra, 2018, p. 15-16.

Recebido para publicação em: 15 jan. 2021. Aprovado em: 18 mar. 2021. 